\title{
Biological and histopathological evaluations of using ozone gas in decontamination of aflatoxinB, in wheat grains
}

\begin{abstract}
Forty eight Sprague-Dawley male rats were divided into six groups including the control group fed standard diet, the group fed on Aflatoxin $\mathrm{B}_{1}\left(\mathrm{AFB}_{1}\right)$ free wheat treated with ozone gas at $20 \mathrm{ppm}$ for $20 \mathrm{~min}$ mixed with standard diet, the group fed on $\mathrm{AFB}_{1}$ free wheat treated with ozone gas at $40 \mathrm{ppm}$ for $20 \mathrm{~min}$ mixed with standard diet, the group fed $\mathrm{AFB}_{1}$ contaminated diet $(2.5 \mathrm{mg} / \mathrm{kg}$ diet $)$, the group fed on $\mathrm{AFB}_{1}$-contaminated wheat ozonation at $20 \mathrm{ppm}$ for $20 \mathrm{~min}$ mixed with standard diet and the group fed on AFB-contaminated wheat ozonation at $40 \mathrm{ppm}$ for $20 \mathrm{~min}$ mixed with standard diet. The results indicated that the animals fed $\mathrm{AFB}_{1}$-contaminated diet alone showed a significant decrease in feed intake compared to the control group. Animals fed $\mathrm{AFB}_{1}$-contaminated wheat treated with ozone showed a significant improvement in feed intake and body weight compared to group fed $\mathrm{AFB}_{1}$-contaminated diet. In addition to animals fed $\mathrm{AFB}_{1}$-contaminated diet $(2.5 \mathrm{mg} / \mathrm{kg}$ diet $)$ untreated for 4 weeks showed a significant increase in levels of the biochemical parameters and levels of createnine and uric acid compared to the control group or the groups fed ozone treated wheat alone or the $\mathrm{AFB}_{1}$-contaminated wheat treated with ozone gas at 20 and $40 \mathrm{ppm}$. On the other hand animal fed on AFB-contaminated wheat treated with ozone showed a significant improvement in all tested parameters. The Glutathione reduced (GSH) level decreased in animal feed on AFB -contaminated wheat when compared with the control. Moreover, GSH value in animal feed on contaminated diet after ozonation was related with control group. The histological examination of the liver and kidney tissues showed the animals fed on $\mathrm{AFB}_{1}$ free diet and treated with ozone showed a significant elimination of the harmful effects in the liver and kidney tissues
\end{abstract}

Keywords: aflatoxin $\mathrm{B}_{1}$, ozonation, wheat, decontamination and biological
Volume 3 Issue 4 - 2017

\author{
El-Desouky TA,' Sharoba AMA, ${ }^{2}$ A ' El- \\ Desouky, ${ }^{2}$ El-Mansy HA, ${ }^{2}$ Khayria Naguib' \\ 'Department of Food Toxicology and Contaminants, National \\ Research Center, Egypt \\ ${ }^{2}$ Department of Food Science Department, Banha University, \\ Egypt
}

Correspondence: El-Desouky TA, Department of Food Toxicology and Contaminants, National Research Center, Dokki, Cairo,Egypt,Email eldesoukyt@yahoo.com

Received: June 22, 2017 | Published: July 19, 2017

\section{Introduction}

A variety of moulds routinely infect the world's cereal crops Under certain field or storage conditions, some moulds can produce toxin metabolites "mycotoxins". Aflatoxins (AFs) are a group of highly carcinogenic mycotoxins produced primarily by the fungus Aspergillus flavus. Within the group of AFs, Aflatoxin $\mathrm{B}_{1}\left(\mathrm{AFB}_{1}\right)$ have been reported to be carcinogenic, teratogenic, tremorgenic, and dermatitic to a wide range of organisms, and known to cause hepatic carcinoma in humans ${ }^{1} \mathrm{AFB}_{1}$ is the most potent of the four naturally occurring AFs because of its remarkable Hepatotoxicity and carcinogenicity, this feed contaminant has been the focus of considerable research since its discovery. AFB is the most potent carcinogenic substance naturally produced by Aspergillus species. $\mathrm{AFB}_{1}$ is classified by the International Agency of Research on Cancer as Group1 human carcinogen. ${ }^{2} \mathrm{AFB}$ has been linked to a specific $\mathrm{G}$ to $\mathrm{T}$ transversion in the codon 249 in the p53 tumor suppressor gene in primary human hepatocellular carcinoma (HCC). ${ }^{3}$ The liver is generally the primary target organ and liver damage has been demonstrated in poultry, fish, rodents and non-human primates fed $\mathrm{AFB}_{1}$. Different species have been observed to exhibit different levels of susceptibility to aflatoxins, an example being that in rats and rainbow trout $\mathrm{AFB}_{1}$ is amongst the most potent carcinogens known, but is only either a very weak carcinogen or even non-carcinogenic in guinea pigs. AFB have been demonstrated to bind covalently to the N7 of guanine in DNA after $\mathrm{P}_{450}$ mediated activation of the $\mathrm{C}_{8}-\mathrm{C}_{9}$ vinyl ether to the highly reactive epoxide. From a toxicological point of view, it is clear that the generation of an 8,9 epoxide of aflatoxin is an important prelude to the toxicity observed ${ }^{4}$ Cytochrome P450 enzymes located in the liver are known to convert AFB1 to compounds such as the highly reactive 8,9 epoxide, aflatoxicol, aflatoxin $\mathrm{Q}_{1}$, aflatoxin $\mathrm{P} 1$, and AFM1 depending on the genetic predisposition of the species. Following its formation, the aflatoxin- 8 , 9-epoxide binds very rapidly to DNA and serum albumin forming aflatoxin-N7-guanine and lysine adducts, respectively. ${ }^{5-7}$ A variety of chemical, physical, and biological treatments have beentested for their ability to reduce or eliminate the AFs in contaminated feeds and foods. Ozone gas is a powerful oxidant capable of reaction with numerous chemical groups ${ }^{8}$ Ozone either completely degrades mycotoxins or causes chemical modifications, reducing their biological activity. Ozone reacts across the 8,9 double bond of the furan ring of $\mathrm{AFB}$ through electrophilic attack,causing the formation of primary ozonides followed by rearrangement into monozonide derivatives such as aldehydes, ketones and organic acids ${ }^{9,10}$ The objective of this study was to evaluate the capability of ozone gas to decontamination of $\mathrm{AFB}_{1}$ in contaminated wheat grain and confirm detoxification using laboratory animals

\section{Material and methods}

\section{Wheat grains}

Wheat grains (Triticum aestivum) were obtained from the South Cairo Mills Company, Cairo, Egypt. 


\section{Production of ozone gas}

Ozone gas was produced from air using ozone generator Model OZO 6 VTTL OZO Max Ltd, Shefford, QuebecCanada. (OZO MAX LTD, shefford, Quebec, Canada) from purified extra dry oxygen feed gas. The amount of output from ozone was controlled by a monitorcontroller having a plug-in sensor on board which is changed for different ranges of ozone concentration and a belt pan in the monitorcontroller allows controlling the concentration in a selected range.

\section{Experimental animals}

Three-month old Sprague-Dawley male rats (120-130g) were purchased from the Animal House Colony, National Research Center, Giza, Egypt. The animals were maintained on a standard diet (protein: $16.04 \%$; fat: $3.63 \%$; fiber: $4.1 \%$, and metabolic energy: $2887 \mathrm{Kcal}$, $\mathrm{Kg})$. After an acclimation period of one week, animals were divided into six groups (8 rats/ group) and housed in filter-top polycarbonate cages housed in a temperature controlled and artificially illuminated room free from any source of chemical contamination

\section{Experimental design}

Animals within different treatment groups were treated daily for four weeks as follows:

i. Group (1): control animals which fed on standard diet.

ii. Group (2): Fed on $\mathrm{AFB}_{1}$ free diet ozonation at 20ppm for 20min.

iii. Group (3): Fed on $\mathrm{AFB}_{1}$ free diet ozonation at 40ppm for $20 \mathrm{~min}$.

iv. Group (4): Fed $\mathrm{AFB}_{1}$-contaminated diet (2.5mg/kg diet).

v. Group (5): Fed on $\mathrm{AFB}_{1}$-contaminated diet ozonation at 20ppm for $20 \mathrm{~min}$

vi. Group (6): Fed on $\mathrm{AFB}_{1}$-contaminated diet ozonation at 40ppm for $20 \mathrm{~min}$.

At the end of the experimentation period (4 weeks), blood samples were collected from all animals from the retro-orbital venous plexus after they had fasted for $12 \mathrm{~h}$ for different biochemical analyses. After the collection of blood samples, all animals were sacrificed and the blood samples were collected in a dry clean centrifuge tubes. The tubes were kept for $30 \mathrm{~min}$. to allow blood to clot before centrifugation at $3000 \mathrm{rpm}$ for $10 \mathrm{~min}$. using cooling centrifuge. Serum was separated and stored at $-20^{\circ} \mathrm{C}$ for analysis. Other samples from the livers and kidneys were excised and fixed in $10 \%$ neutral formalin for histopathological studies. The tissue samples were dehydrated in ascending grades of ethanol, cleaned in xylene and embedded in paraffin. Sections $(8 \mu \mathrm{m})$ from the investigated organs were cut and stained with hematoxylin and eosin (H\&E). For the histochemical investigations Crossman's stain was carried out to demonstrate connective tissue in liver. ${ }^{11}$

\section{Biochemical assay}

The activities of serum alanine transaminase (ALT) and aspartate transaminase (AST) were determined according to. ${ }^{12}$ The determination of alkaline phosphatase (ALP) in serumwas performed according to the method described by Roy ${ }^{13}$ Total Antioxidant Capacity level was determined using the enzymatic colorimetric method according to. ${ }^{14}$ Glutathione was determined in blood according to the methods. ${ }^{15}$ Uric acid level was determined using the enzymatic colorimetric method. ${ }^{16}$ Creatinine was determined in serum using commercial kits purchased from Biodiagnostic Company., Cairo, Egypt. According to. ${ }^{17}$ All kits obtained from Biodiagnostic Company., Cairo, Egypt.

\section{Statistical analysis}

All data were statistically analyzed using the General Linear Model Procedure of the SPSS var 18. The significance of the differences among treatment groups was determined by Waller-Duncan k-ratio. ${ }^{18}$ All statements of significance were based on probability of $\mathrm{P}<0.05$.

\section{Results and discussion}

The acute toxicity of $\mathrm{AFB}_{1}$ firstly appeared as a significant decrease in feed intake. Animals fed $\mathrm{AFB}_{1}$-contaminated diet alone showed a significant decrease in feed intake compared to the control group or the groups fed ozone treated wheat or the $\mathrm{AFB}_{1}$-contaminated wheat treated with ozone gas (Figure 1). Our current results in Figure 2 showed that animals fed $\mathrm{AFB}_{1}$-contaminated diet $(2.5 \mathrm{mg} / \mathrm{kg}$ diet $)$ alone for 4 weeks showed a significant decrease in body weight compared to the control group or the groups fed ozone treated wheat or the $\mathrm{AFB}_{1}$-contaminated wheat treated with ozone. Results in the indicated that animals fed $\mathrm{AFB}_{1}$-contaminated wheat treated with ozone showed a significant improvement in body weight compared to group fed $\mathrm{AFB}_{1}$-contaminated diet alone.The results indicated that ingestion of $\mathrm{AFB}_{1}$ resulted in a significant decrease in food intake and consequently the body weight gain was also reduced. The reduced feed intake may indicate protein catabolism, thereby contributing to the observed kidney injury and causing impaired glomerular filtration. ${ }^{19}$ On the other hand, the decrease in body weight in the animals fed $\mathrm{AFB}_{1}$-contaminated diet alone may be due to the effects of $\mathrm{AFB}$ on the balance between orexigenic and anorexigenic circuits that regulate the homeostatic loop of body weight regulation, leading to cachexia. ${ }^{20}$ Another mechanism for the reduction of body weight due to AFs ingestion could be that AFs ingestion alters various digestive enzymatic activities that give rise to a malabsorption syndrome, characterized by steatorhea, hypocarotenoidemy, and to lowering of bile, pancreatic lipase, trypsin, and amylase. ${ }^{21}$ Similar to our results, ${ }^{22}$ reported that decrease in weight gains caused by the AFs corn was eliminated by treatment of the corn with ozone. Of importance is the fact that performance was not affected by treatment of control corn with ozone. Feed conversion (feed: body weight gain) was not affected by any of the treatments and no mortalities were recorded.

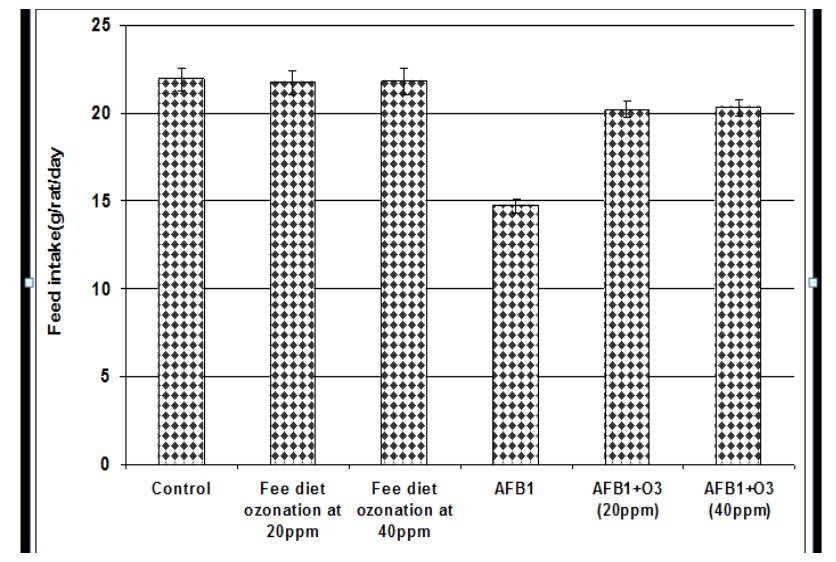

Figure I Effect of ozone treated $\mathrm{AFB}_{1}$-contaminated wheat alone or treated with ozone on feed intake in rats. 


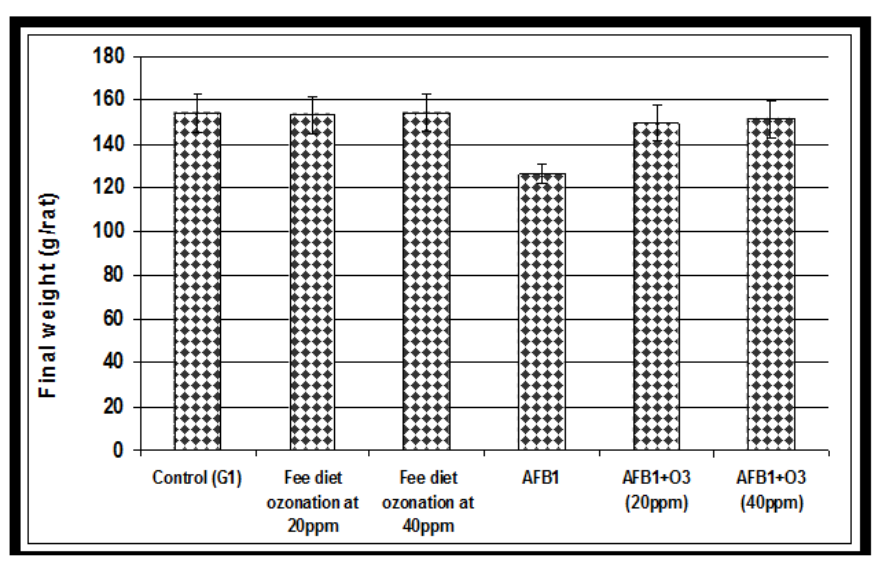

Figure 2 Effect of ozone treated and $\mathrm{AFB}_{1}$-contaminated wheat alone or treated with ozone on final body weight in rats.

\section{The biochemical study}

The results of the present study revealed that AFB1 induced severe toxicological effects on serum biochemical parameters tested. The effects of different treatments on ALT, AST and ALP activity in rats are presented in (Table 1). Animals fed $\mathrm{AFB}_{1}$-contaminated diet $(2.5 \mathrm{mg} / \mathrm{kg}$ diet $)$ alone for 4 weeks showed a significant increase in ALT, AST and ALP compared to the control group or the groups fed ozone treated wheat alone or the AFB1 -contaminated wheat treated with ozone gas at 20 and $40 \mathrm{ppm}$. Analysis of variance indicated that rats fed wheat-contaminated with AFB1 treated with ozone showed a significant improvement in ALT, AST and ALP although these parameters were still higher than the control. The activity of ALT and AST is a sensitive indicator of acute hepatic necrosis, and hepatobiliary disease. ${ }^{23}$ The increases in ALT, AST and ALP in AFstreated animals are indicative for changes in the hepatic tissues and biliary system. ${ }^{24}$ The effect of ozonation on createnine and uric acid was depicted in Table 2. We observed the significant increase in createnine and uric acid levels in animals fed AFB1-contaminated wheat when compared to the other treated groups. The effects of ozone treatment on Total Antioxidant Capacity (TAC) and GSH are presented in Table 3. The decrease in (TAC) with $\mathrm{AFB}_{1}$ group might indirectly lead to an increase in oxidative DNA damage. ${ }^{25}$ The GSH level decreased in animal feed on AFB1-contaminated wheat when compared with the control or the treated groups. Moreover, GSH value in animal feed on contaminated diet after ozonation was related with control group ${ }^{26}$ reported that GSH, a key antioxidant, is an important constituent of intracellular protective mechanisms against various noxious stimuli, including oxidative stress. GSH depletion in hepatocytes mitochondria has been shown to be an important mechanism in the pathology of experimental liver injury. It has been reported that higher GSH levels help to lower $\mathrm{AFB}_{1}$ toxicity through conjugation with the toxin. ${ }^{27}$ Several studies on the mechanisms of mycotoxins induced liver injury have demonstrated that glutathione plays an important role in the detoxification of the reactive and toxic metabolites of these mycotoxins, and the liver necrosis begins when the glutathione stores are almost exhausted..$^{28}$

Table I Effect of ozone treatment on liver function parameters in rats fed $\mathrm{AFB}_{1}$-contaminated diet $(2.5 \mathrm{mg} / \mathrm{kg}$ diet)

\begin{tabular}{llll}
\hline \multirow{2}{*}{ Groups } & \multicolumn{2}{l}{ Parameters (mean \pm SE)* } \\
\cline { 2 - 4 } & ALT (U/L) & AST (U/L) & ALP (U/L) \\
\hline Control & $30.41 \pm 0.20^{\mathrm{a}}$ & $56.34 \pm 0.2 \mathrm{I}^{\mathrm{a}}$ & $82.35 \pm 0.2 \mathrm{I}^{\mathrm{a}}$ \\
Fee diet ozone treated at 20ppm & $30.32 \pm 0.13^{\mathrm{a}}$ & $56.69 \pm 0.06^{\mathrm{a}}$ & $82.65 \pm 0.03^{\mathrm{a}}$ \\
Fee diet ozone treated at 40ppm & $30.24 \pm 0.0 \mathrm{I}^{\mathrm{a}}$ & $56.52 \pm 0.18^{\mathrm{a}}$ & $82.39 \pm 0.13^{\mathrm{a}}$ \\
$\mathrm{AFB}_{\text {I }}$ & $48.63 \pm 0.0 \mathrm{I}^{\mathrm{b}}$ & $70.29 \pm 0.07^{\mathrm{b}}$ & $144.5 \mathrm{I} \pm 0.1 \mathrm{I}^{\mathrm{b}}$ \\
$\mathrm{AFB}_{\text {, after ozonation at }(20 \mathrm{ppm})}$ & $31.27 \pm 0.02^{\mathrm{c}}$ & $64.29 \pm 0.02^{\mathrm{c}}$ & $88.440 \pm 0.02^{\mathrm{c}}$ \\
AFB $_{\text {, after ozonation at }}(40 \mathrm{ppm})$ & $31.16 \pm 0.07^{\mathrm{c}}$ & $64.01 \pm 0.08^{\mathrm{c}}$ & $88.08 \pm 0.27^{\mathrm{c}}$ \\
\hline
\end{tabular}

*Within each column, means superscript with the same letter are not significant different at $p \leq 0.05$.

Table 2 Effect of ozone treated on kidneysfunction parameters in rats fed $\mathrm{AFB}_{-}$-contaminated diet $\left(2.5 \mathrm{mg} / \mathrm{kg}\right.$ diet) $(\mathrm{mean} \pm \mathrm{SE})^{*}$

\begin{tabular}{lll}
\hline Groups & Creatinine $(\mathbf{m g} / \mathbf{d l})$ & Uric acid $(\mathbf{m g} / \mathbf{d l})$ \\
\hline Control & $0.3680 \pm 0.006^{\mathrm{a}}$ & $4.19 \pm .039^{\mathrm{a}}$ \\
Fee diet ozone treated at 20ppm & $0.3620 \pm 0.003^{\mathrm{a}}$ & $4.16 \pm 03^{\mathrm{a}}$ \\
Fee diet ozone treated at $40 \mathrm{ppm}$ & $0.3740 \pm 0.005^{\mathrm{a}}$ & $4.17 \pm .02^{\mathrm{a}}$ \\
$\mathrm{AFB}_{\text {, }}$ & $0.7480 \pm 0.006^{\mathrm{b}}$ & $6.31 \pm 0 \mathrm{I}^{\mathrm{b}}$ \\
$\mathrm{AFB}_{\text {, after ozonation at }}(20 \mathrm{ppm})$ & $0.4220 \pm 0.006^{\mathrm{c}}$ & $4.34 \pm .0 \mathrm{I}^{\mathrm{c}}$ \\
$\mathrm{AFB}_{\text {, after ozonation at }}(40 \mathrm{ppm})$ & $0.4120 \pm 0.004^{\mathrm{c}}$ & $4.32 \pm .02^{\mathrm{c}}$ \\
\hline
\end{tabular}

*Within each column, means superscript with the same letter are not significant different at $\mathrm{p} \leq 0.05$. 
Table 3 Effect of ozone treatment on total antioxidant capacity (TAC) and glutathione reduced (GSH) in rats fed AFB - contaminated diet (2.5mg/kg diet) for 4weeks

\begin{tabular}{|c|c|c|}
\hline Groups & TAC ( $\mu$ mol./g Liver tissue) & GSH (mg/dL) \\
\hline Control & 104.26 & 0.548 \\
\hline Fee diet ozone treated at 20ppm & 104.31 & 0.544 \\
\hline Fee diet ozone treated at 40ppm & 104.33 & 0.543 \\
\hline $\mathrm{AFB}_{1}$ & 53.72 & 0.067 \\
\hline $\mathrm{AFB}_{1}$ after ozonation at (20ppm) & 85.75 & $0.48 I$ \\
\hline $\mathrm{AFB}_{1}$ after ozonation at (40ppm) & 85.71 & 0.477 \\
\hline
\end{tabular}

\section{The histopathological study}

The biochemical results were confirmed by the histological examination in liver and kidney tissues. The histological examination of the structure of liver in the control group was normal hepatocytes and central (Figure 3). Liver of rats in group four that fed $\mathrm{AFB}_{1}-$ contaminant diet $(2.5 \mathrm{mg} / \mathrm{kg}$ feed $)$ alone showed enlarged portal area and dilated thick wall portal vein and also appeared accumulation of cellular infiltration and fibrous tissues around proliferated bile ducts thick (arrow) (Figure 4). Rats fed on $\mathrm{AFB}_{1}$ free diet and treated with ozone showed the hepatic cells and central vein are nearly normal (Figure 5). In the other hand, animal in group fed $\mathrm{AFB}_{1}$-contaminated diet after ozonation at 20 and/or40 ppm ozone gas showed the area around the central vein is nearly normal and nearly normal hepatocytes and the damaged area around the portal tracts is not noticed (Figure 6). The liver is the main target organ for AFs and chronic exposure to low levels in foodstuffs cause liver fibrosis and primary liver cancer. ${ }^{29}$ Microscopic examination of kidney section of control rats showed the normal structure of renal tissue in convoluted tubules and the Bowman capsule (Figure 7). But rats fed $\mathrm{AFB}_{1}$-contaminant diet alon showed distal tubules have fatty degeneration and eosinophilic cytoplasm as well as pyknotic nuclei. Interstatial edema and inflammation also present (Figure 8). While rats fed on $\mathrm{AFB}_{1}$ free diet and treated with ozone showed the nearly normal structural of renal tissue and normal convoluted tubules and the Bowman capsule also rats fed $\mathrm{AFB}_{1}$-contaminated diet after ozonation (Figures 9) (Figures $10)$. In the current study, animals' fedAFB free diet after ozonation (ozone gas treated wheat alone) did not show any significant effects however, when the $\mathrm{AFB}_{1}$-contaminated wheat grain after ozonation, a significant improvement was observed in the serum biochemical parameters tested and histological examination in liver and kidney tissues. This could be due to the $\mathrm{AFB}_{1}$ been degraded after ozone treatment of the contaminated wheat. These results were in agreement with. ${ }^{22}$ The primary reaction site of ozone in AFB1 and is the C8-C9 double bond at the terminal furan. This site has been associated with $\mathrm{AFB}_{1}$ toxicity, mutagenicity, and carcinogenic. ${ }^{5}$ This reaction resulted in the formation of aflatoxinmolozonide which is further change to aflatoxinozonide. This compound is unstable and change to aldehydes, Ketones, acids and $\mathrm{CO}_{2}$ (Figure 11). Ozone is a decomposes to form oxygen gas and therefore can be classified as a no persistent chemical; however, it must be generated at the location of its intended use.

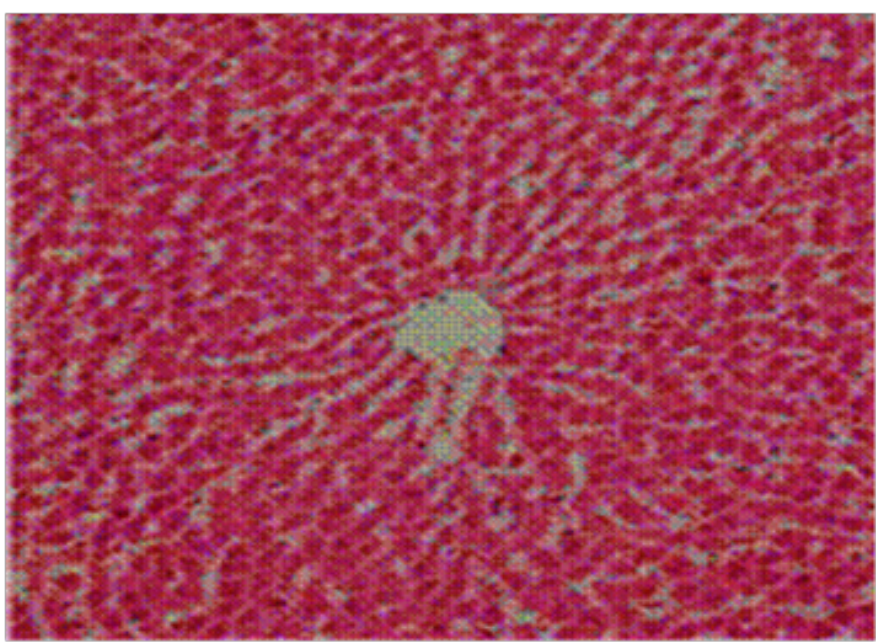

Figure 3 Section in liver of control rats showing the normal histological structure of liver lobule, central vein and hepatocytes separated with blood sinusoids.

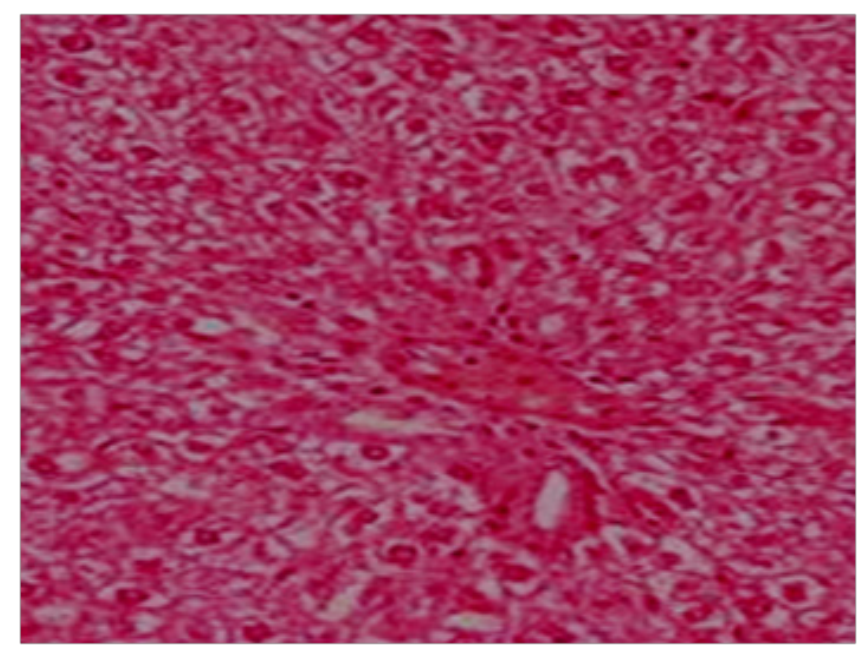

Figure 4 Section in liver of rat fed $A F B_{1}$-contaminated diet showing thickening portal tract with cellular debris and periportal fibrosis. The hepatocytes showing vacuolar degeneration and nuclear pleomorphism. 


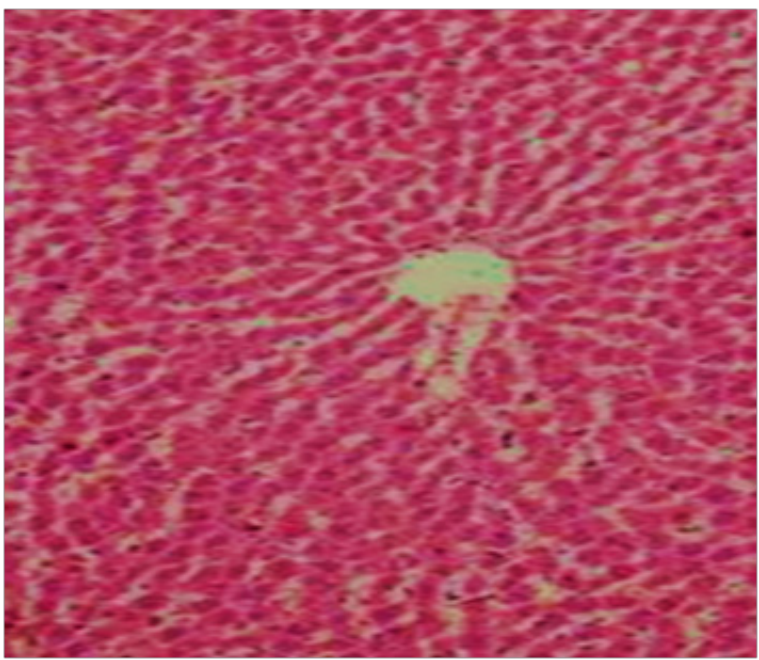

Figure 5 Section in liver of group fed on AFB, free diet and treated with ozone gas showing the hepatic cells and central vein are nearly.

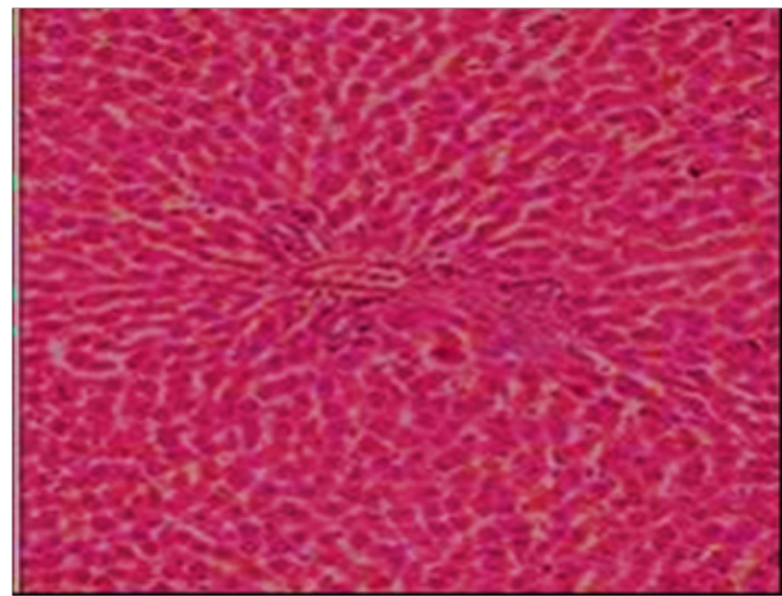

Figure 6 Section in liver of rat fed $\mathrm{AFB}_{1}$-contaminated diet after ozonation showing significant improvements in liver tissues and normal hepatocytes.

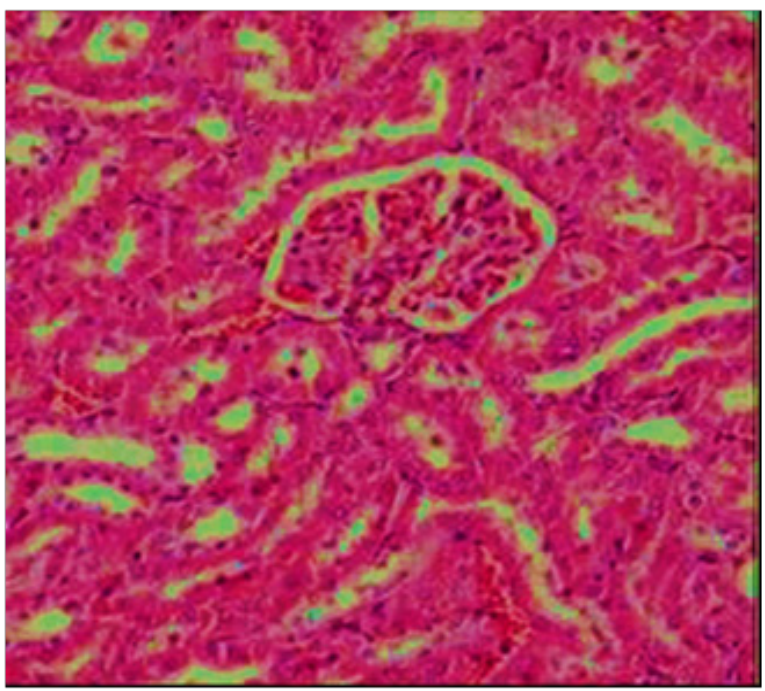

Figure 7 Section in kidney from control rat showing the normal convoluted tubules and the Bowman capsule (H\&E200).

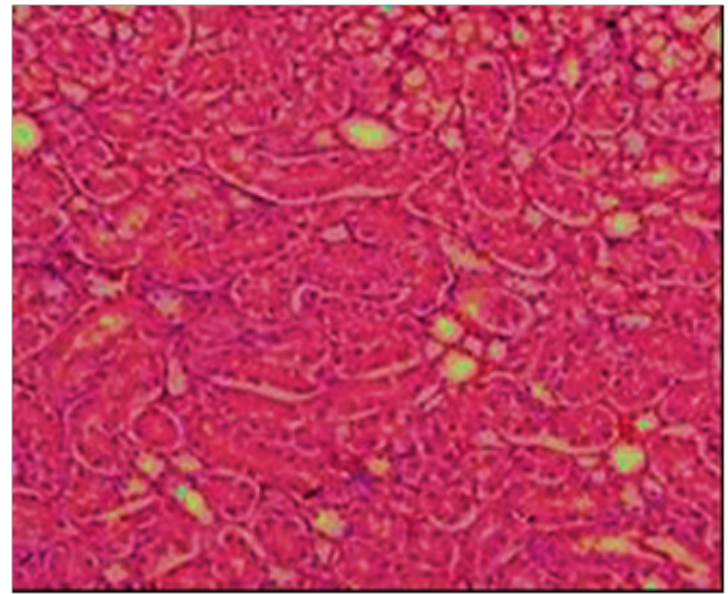

Figure 8 Section in kidney of of rat fed AFB,-contaminated diet showing some distal tubules have fatty degeneration and eosinophilic cytoplasm as well as pyknotic nuclei (arrow) or hyaline casts (circle). Interstitial edema and inflammation also present (H\&E 200).

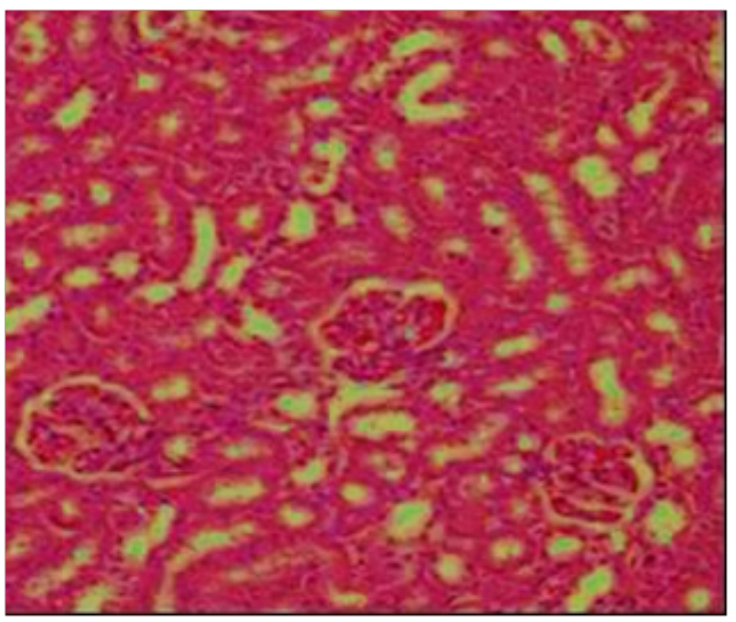

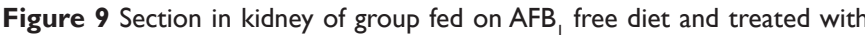
ozone gas showing nearly normal convoluted tubules and the Bowman corpuscle (H \&E 200).

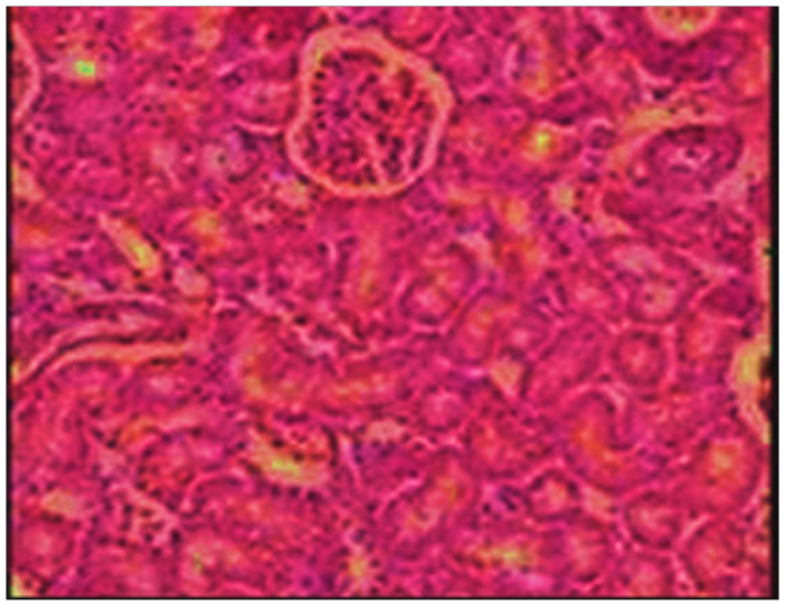

Figure 10 Section in kidney of rat fed AFB -contaminated diet after ozonation showing significant improvements in liver tissues and normal hepatocytes (H\&E 200).

Citation: El-Desouky TA, Sharoba AMA, El-Desouky Al, et al. Biological and histopathological evaluations of using ozone gas in decontamination of aflatoxinB in wheat grains. MOJ Toxicol. 20I7;3(4):76-8I. DOI: 10.15406/mojt.2017.03.00057 


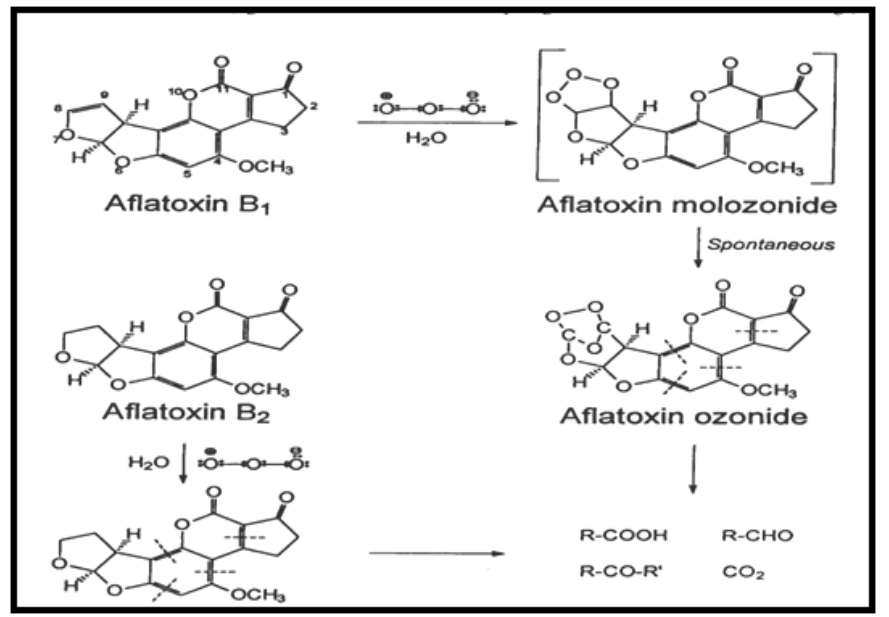

Figure II Mechanism for the addition of ozone to AFs accordting to McKenzie et al. ${ }^{22}$

\section{Conclusion}

Finally from this study, we can conclude that the use of ozone gas to reduction and or removal AFB is biologically safe and does not produce any secondary compounds that may cause toxicity. Therefore, ozone gas can be used as one of the most effective and safe methods to removal of $\mathrm{AFB}_{1}$.

\section{Acknowledgements}

None.

\section{Conflict of interest}

The author declares no conflict of interest.

\section{References}

1. Kumar V, Basu MS, Rajendran TP. Mycotoxin research and mycoflora in some commercially important agricultural commodities. Crop Protection. 2008;27:891-905.

2. Aflatoxins. IARC Monographs on the evaluation of Carcinogenic Risks to Humans. International Agency for Research on Cancer. 1993. 56:243-395.

3. Essigmann JM, Croy RG, Nadzan AM, et al. Structural identification of the major DNA adduct formed by aflatoxin $\mathrm{B}_{1}$ In vitro. Proc Natl Acad Sci. 1977;74(5):1870-1874.

4. Papp E, H-Otta K, Záray G, et al. Liquid chromatographic determination of aflatoxins. Micro chemical Journal. 2002;73:39-46.

5. Eaton DL, Groopman JD. The Toxicology of Aflatoxins: Human Health, Veterinary and Agricultural Significance. USA: Academic Press; 1994. p. 1-544.

6. Bennett JW, Klich M. Mycotoxins. Clin Microbiol Rev. 2003;16(3):497516.

7. Kuhn DM, Ghannoum MA. Indoor mold, toxigenic fungi, and Stachybotryschartarum: Infectious disease perspective. Clin Microbiol Rev. 2003;16(1):144-172.

8. El Desouky TA, Sharoba AMA, El Desouky AI, et al. Effect of Ozone gas on degradation of aflatoxin $\mathrm{B}_{1}$ and Aspergillusflavusfungal. $J$ Environment Analytic Toxicol. 2012;2:128.

9. McKenzie KS, Kubena LF, Denvir AJ, et al. Aflatoxicosis in turkey poults is prevented by treatment of naturally contaminated corn with ozone generated by electrolysis. Poult Sci. 1998;77(8):1094-1102.
10. Lemke SL, Mayura K, Ottinger SE, et al. Assessment of the estrogenic effects of zearalenone after treatment with ozoneutilizing the mouse uterine weight bioassay. J Toxicol Environ Health A. 1999;56(4):283295.

11. Culling CF. Handbook of histopathological technique. 2nd ed. UK: Butterworths; 1963.

12. Reitman S, Frankel S. Colorimetric method for aspartate and alanine transferases. American Journal of Clinical Pathology. 1957;28:56-63.

13. Roy AV. Rapaid method for determining alkaline phosphatase activity in serum with thymolphthalin monophosphate. Journal Clinical Chemistry. 1970;16(5):431-36.

14. Koracevive D, Koracevic G. The colorimetric methods for determination of total antioxidant capacity. J Clin Pathol. 2001;54(5):356-361.

15. Anderson ME. Enzymatic and chemical methods for the determination of Glutathione. In: Glutathione, Dolphin D, editors. Chemical, biochemical and medical aspects. USA: John Wiley and Sons,; 1989. p. $339-365$

16. Barham D, Trinder P. An improved color reagent for the determination of blood glucose by oxidative system. Analyst. 1972;97(151):142-145.

17. Bartles H, Bohmer M, Heirli C. Serum creatinine determination without protein preciptation. Clin Chim Acta. 1972;37:193-197.

18. Waller RA, Duncan DB. A Bayes rule for the symmetric multiple comparison problems. Journal of the American Statistical Association. 1969;64(328):1484-1503.

19. Tessari EN, Oliveira CA, Cardoso AL, et al. Effects of aflatoxin $B_{1}$ and fumonisin $\mathrm{B}_{1}$ on body weight, antibody titres and histology of broiler chicks. Br Poult Sci. 2006;47(3):357-364.

20. Rastog RA, Srivastava AK, Rastogi AK. Biochemical changes induced in liver and serum of aflatoxin B1-treated male Wister rats:preventive effect of picroliv. Pharmacology and Toxicology. 2001;88(2):53-58.

21. Osborne DJ, Huff WE, Hamilton PB, et al. Comparison of ochratoxin, aflatoxin and T-2 toxin for their effects on selected parameters related to digestion and evidence for specific metabolism of carotenoids in chickens. Poultry Science. 1982;61(8):1646-1652.

22. McKenzie KS, Sarr AB, Mayura K, et al. Oxidative degradation and detoxification of mycotoxins using a novel source of ozone. Food Chemical Toxicology. 1997;35(8):807-820.

23. Kaplan MM. Laboratory tests. In: Schiff L, Schiff ER, editors. Diseases of the Liver JB. USA; 1987. p. 1-219.

24. Abdel Wahhab MA, Nada SA, Khalil FA. Physiological and toxicological responses in rats fed aflatoxin-contaminated diet with or without sorbent materials. Animal Feed Science Technology. 2002;97(3-4):209-219.

25. Choi KC, Chung WT, Kwon JK, et al. Inhibitory effects of quercetin on aflatoxin B1-induced hepatic damage in mice. Food Chemical Toxicology. 2010;48(10):2747-2753.

26. Shyamal S, Latha PG, Suja SR, et al. Hepatoprotective effect of three herbal extracts on aflatoxin B1-intoxicated rat liver. Singapore Medical. 2011;51(4):326-331.

27. Yuan SS, Tsai KB, Chung YF, et al. Aberrant expression and possible involvement of the leptin receptor in endometrial cancer. Gynecol Oncol. 2004;92(3):769-775.

28. Mitchell JR, Jollow DJ, Potter WZ, et al. Acetaminophen-induced hepatic necrosis. IV. Protective role of glutathione. J Pharmacol Exp Ther. 1973;187(1):211-217.

29. Roberts TA, Baird-Parker AC, Tompkin RB. Toxigenic fungi: Aspergillus. Microorganisms in Food. Microbiological Specification of Food Pathogens-ICMSF. 19th ed. UK: Lackie Academic and Professional; 1996. p. 347-381. 